\title{
Clinical factors affecting perioperative outcomes in robot-assisted radical prostatectomy
}

\author{
TOMOHIKO MURAKAMI, SATOSHI OTSUBO, RYO NAMITOME, MASAKI SHIOTA, JUNICHI INOKUCHI, \\ ARIO TAKEUCHI, EIJI KASHIWAGI, KATSUNORI TATSUGAMI and MASATOSHI ETO
}

\author{
Department of Urology, Graduate School of Medical Sciences, Kyushu University, Fukuoka 812-8582, Japan
}

Received June 29, 2018; Accepted September 12, 2018

DOI: $10.3892 / \mathrm{mco} .2018 .1718$

\begin{abstract}
The present study investigated clinical factors affecting perioperative outcomes in robot-assisted radical prostatectomy (RARP). The study included 625 Japanese cases treated with RARP between 2009 and 2017. The association between clinical factors (age, overweight status, prostate volume, clinical T-stage, nerve sparing, lympho-node dissection, and the number of experienced cases) and perioperative outcomes (operation time, estimated blood loss, catheterization duration, and perioperative complication) were analyzed. Results revealed that overweight status, prostate volume, lymph-node dissection, and the number of experienced cases were associated with operation time. For estimated blood loss, the identified risk factors were overweight status, prostate volume, nerve sparing, lymph-node dissection, and the number of experienced cases. Lymph-node dissection and the number of experienced cases were also associated with catheterization duration. Additionally, only lymph-node dissection was associated with increased perioperative complication. Taken together, the present study identified several clinical factors affecting perioperative outcomes in RARP. This information may help surgeons to estimate perioperative outcomes as well as to inform patients.
\end{abstract}

\section{Introduction}

Prostate cancer is the most common cancer in men except cutaneous cancer, and the second-leading cause of cancer-related mortality among men in developed countries (1). Surgical intervention is curative treatment for low- to intermediate-risk localized prostate cancer with established evidence $(2,3)$, and has become applied to high-risk or

Correspondence to: Dr Masaki Shiota, Department of Urology, Graduate School of Medical Sciences, Kyushu University, 3-1-1 Maidashi, Higashi-ku, Fukuoka 812-8582, Japan

E-mail: shiota@uro.med.kyushu-u.ac.jp

Key words: comorbidity, perioperative outcome, prostate cancer, robot-assisted radical prostatectomy, risk factor advanced prostate cancer $(3,4)$. The intervention has even also recently been challenged as a treatment for metastatic prostate cancer in clinical trials (5).

In the past decade, robot-assisted radical prostatectomy (RARP) was rapidly expanding globally due to its minimally invasive, but precise and fine procedures. Now, RARP has become the most common surgical intervention in developed countries. Due to these advantages, RARP is associated with reduced blood loss, reduced transfusion rate and reduced hospital stay as well as favorable perioperative complication rate, compared with open or laparoscopic radical prostatectomy (6-8). However, still, adverse perioperative outcomes have still occurred even in RARP (9).

Perioperative outcomes are critical to both patients and surgeons, where several factors have been identified to affect in RARP. For example, obesity can result in adverse perioperative outcomes based on technical difficulty during procedures (10-12), which is supposed to also affect oncological outcome among men treated with open radical prostatectomy, but not with laparoscopic or robot-assisted radical prostatectomy $(13,14)$. Obesity has been recognized to be more common in Western countries, but relatively rare in Asian countries, suggesting that this difference may affect perioperative outcomes in RARP. In addition, several clinical factors such as prostate volume and number of experienced cases have been reported to affect perioperative outcomes from Western countries (7). However, reports from Asia on perioperative outcomes in RARP are scarce. Therefore, to clarify perioperative outcomes as well as clinical factors affecting perioperative outcomes in RARP among Asian population, we investigated perioperative outcomes among Japanese men in our institution.

\section{Patients and methods}

This study enrolled case series who underwent RARP as primary treatment for prostate cancer at Kyushu University Hospital (Fukuoka, Japan) from June 2009 to March 2017. The eligibility criteria included: i) Histopathologically-diagnosed adenocarcinoma of the prostate, and ii) no evidence of metastasis by imaging modality including computed tomography scan and bone scintigraphy. The exclusion criteria included: i) Conversion to distinct procedures such as open radical prostatectomy, and ii) major cardiovascular, liver, or renal 
Table I. Univariate and multivariate analyses of clinical factors affecting total operation time.

\begin{tabular}{|c|c|c|c|c|}
\hline \multirow[b]{2}{*}{ Variable } & \multicolumn{2}{|c|}{ Univariate analysis } & \multicolumn{2}{|c|}{ Multivariate analysis } \\
\hline & Mean (SEM) & P-value & Least squares mean (SEM) & P-value \\
\hline \multicolumn{5}{|l|}{ Age, years } \\
\hline$<65$ & $245.1(3.6)$ & & $272.6(3.6)$ & \\
\hline$\geq 65$ & $246.6(3.3)$ & 0.75 & $268.2(3.8)$ & 0.20 \\
\hline \multicolumn{5}{|l|}{ Overweight } \\
\hline Absence & $240.9(2.9)$ & & $261.2(3.5)$ & \\
\hline Presence & $257.0(4.3)$ & $0.0019^{\mathrm{b}}$ & $279.6(3.9)$ & $<0.0001^{\mathrm{d}}$ \\
\hline \multicolumn{5}{|l|}{ Prostate volume, $\mathrm{ml}$} \\
\hline$<30$ & $241.2(3.0)$ & & $259.3(3.1)$ & \\
\hline$\geq 30,<50$ & $253.2(4.4)$ & & $269.9(3.7)$ & \\
\hline$\geq 50$ & $256.7(9.0)$ & $0.037^{\mathrm{a}}$ & $282.0(6.5)$ & $0.0002^{\mathrm{c}}$ \\
\hline \multicolumn{5}{|l|}{ cT-stage } \\
\hline cT1 & $227.2(4.1)$ & & $267.1(3.8)$ & \\
\hline $\mathrm{cT} 2$ & $248.9(2.9)$ & & $270.2(3.1)$ & \\
\hline cT3 & $307.7(9.2)$ & $<0.0001^{\mathrm{d}}$ & $273.9(7.1)$ & 0.62 \\
\hline \multicolumn{5}{|l|}{ Nerve sparing } \\
\hline None & $255.4(3.0)$ & & $269.2(3.4)$ & \\
\hline Ipsilateral & $230.2(5.3)$ & & $270.5(4.7)$ & \\
\hline Bilateral & $231.5(5.5)$ & $<0.0001^{\mathrm{d}}$ & $271.5(4.8)$ & 0.89 \\
\hline \multicolumn{5}{|l|}{ Lympho-node dissection } \\
\hline No procedure & $214.3(2.2)$ & & $225.7(3.6)$ & \\
\hline Underwent procedure & $302.4(2.9)$ & $<0.0001^{\mathrm{d}}$ & $315.1(4.0)$ & $<0.0001^{\mathrm{d}}$ \\
\hline \multicolumn{5}{|c|}{ Number of experienced cases } \\
\hline $1-200$ & $232.8(4.2)$ & & $267.3(4.1)$ & \\
\hline $201-400$ & $261.1(4.2)$ & & $284.3(4.0)$ & \\
\hline $401-625$ & $244.0(4.0)$ & $<0.0001^{\mathrm{d}}$ & $259.6(4.0)$ & $<0.0001^{\mathrm{d}}$ \\
\hline
\end{tabular}

${ }^{\mathrm{a}} \mathrm{P}<0.05 ;{ }^{\mathrm{b}} \mathrm{P}<0.01 ;{ }^{\mathrm{c}} \mathrm{P}<0.001 ;{ }^{\mathrm{d}} \mathrm{P}<0.0001$. SEM, standard error of mean.

diseases, and/or other severe comorbidities intolerable to operation. This study was performed in accordance with the principles described in the Declaration of Helsinki and the Ethical Guidelines for Epidemiological Research enacted by the Japanese Government, and was approved by the Ethics Committee of Kyushu University (Fukuoka, Japan). The right of opt-out was provided to all patients.

RARP was performed by seven surgeons using the da Vinci Surgical System ( $\mathrm{S}$ and $\mathrm{Si}$, Intuitive Surgical, Sunnyvale, CA, USA). Basically, the transperitoneal six-port technique was employed in the Trendelenburg position accompanied with the lithotomy position. Nerve sparing was performed by combination of antegrade and retrograde approaches, and athermal technique, based on the risk of extraprostatic extension determined by preoperative cancer risk $(15,16)$, and preoperative patients' potency and preference. Lympho-node dissection for the bilateral regions along the external and internal iliac vessels and within the obturator fossa was performed according to the operation date based on the risk of lympho-node involvement determined by preoperative cancer risk $(15,16)$. Before catheter removal, cystography was performed to check the urinary leakage based on the surgeons' decision.

All data were collected prospectively, including the following parameters: Age, the presence of overweight defined as a body-mass index $\geq 25 \mathrm{~kg} / \mathrm{m}^{2}$, estimated prostate volume at diagnosis by trans-rectal ultrasound examination, prostate-specific antigen at diagnosis, clinical and pathological stages, biopsy and pathological Gleason score, resection margin status, and lymph-node involvement, as well as the operation procedures of nerve sparing and lymph-node dissection. Perioperative outcome parameters such as operation time defined as time from skin incision to the end of skin closure, estimated blood loss, catheterization duration defined as time to removal of urethral catheter, and postoperative complication classified using the Dindo modification of the Clavian Grading System (17) during 30 days postoperation were also collected.

All statistical analyses were performed using JMP 13 software (SAS Institute, Inc., Cary, NC, USA). Univariate and multivariate analyses were performed using regression models. All P-values were two-sided and $\mathrm{P}<0.05$ was considered to indicate a statistically significant difference. 
Table II. Univariate and multivariate analyses on clinical factors affecting estimated blood loss.

\begin{tabular}{|c|c|c|c|c|}
\hline \multirow[b]{2}{*}{ Variable } & \multicolumn{2}{|c|}{ Univariate analysis } & \multicolumn{2}{|c|}{ Multivariate analysis } \\
\hline & Mean (SEM) & P-value & Least squares mean (SEM) & P-value \\
\hline \multicolumn{5}{|l|}{ Age, years } \\
\hline$<65$ & $298.2(19.1)$ & & $363.2(27.1)$ & \\
\hline$\geq 65$ & $259.6(17.4)$ & 0.14 & $354.9(28.3)$ & 0.75 \\
\hline \multicolumn{5}{|l|}{ Overweight } \\
\hline Absence & $238.8(15.3)$ & & $304.7(26.6)$ & \\
\hline Presence & $361.6(22.7)$ & $<0.0001^{\mathrm{d}}$ & $413.4(29.1)$ & $<0.0001^{\mathrm{d}}$ \\
\hline \multicolumn{5}{|l|}{ Prostate volume, $\mathrm{ml}$} \\
\hline$<30$ & $265.0(16.2)$ & & $314.3(23.4)$ & \\
\hline $30 \leq x<50$ & $275.8(23.4)$ & & $326.7(28.2)$ & \\
\hline$\geq 50$ & $388.0(47.8)$ & 0.052 & $436.1(48.7)$ & $0.046^{\mathrm{a}}$ \\
\hline \multicolumn{5}{|l|}{ cT-stage } \\
\hline cT1 & $305.5(23.2)$ & & $401.8(28.7)$ & \\
\hline cT2 & $263.4(16.2)$ & & $365.0(23.2)$ & \\
\hline cT3 & $276.1(51.5)$ & 0.33 & $310.3(53.8)$ & 0.24 \\
\hline \multicolumn{5}{|l|}{ Nerve sparing } \\
\hline None & $251.1(16.3)$ & & 307.7 (25.9) & \\
\hline Ipsilateral & $264.9(28.4)$ & & $336.8(35.2)$ & \\
\hline Bilateral & $377.3(29.7)$ & $0.0009^{c}$ & $432.7(36.1)$ & $0.0039^{\mathrm{b}}$ \\
\hline \multicolumn{5}{|l|}{ Lympho-node dissection } \\
\hline No procedure & $248.2(16.0)$ & & $286.7(27.0)$ & \\
\hline Underwent procedure & $328.9(21.4)$ & $0.0026^{\mathrm{b}}$ & $431.4(30.0)$ & $<0.0001^{\mathrm{d}}$ \\
\hline \multicolumn{5}{|c|}{ Number of experienced cases } \\
\hline $1-200$ & $338.7(22.5)$ & & $412.3(31.2)$ & \\
\hline $201-400$ & $218.4(22.5)$ & & $300.2(30.0)$ & \\
\hline $401-625$ & $274.5(21.2)$ & $0.0009^{c}$ & $364.7(30.1)$ & $0.0018^{\mathrm{b}}$ \\
\hline
\end{tabular}

${ }^{\mathrm{a}} \mathrm{P}<0.05 ;{ }^{\mathrm{b}} \mathrm{P}<0.01 ;{ }^{\mathrm{C}} \mathrm{P}<0.001 ;{ }^{\mathrm{d}} \mathrm{P}<0.0001 . \mathrm{SEM}$, standard error of mean.

\section{Results}

This study enrolled a total of 625 Japanese men who underwent RARP for prostate cancer. As shown in Table S1, the patients' median age was 65 years [interquartile range (IQR), 61-69 years]. Median body-mass index was $23.7 \mathrm{~kg} / \mathrm{m}^{2}$ (IQR, $22.0-25.6 \mathrm{~kg} / \mathrm{m}^{2}$ ), where overweight was recognized in 195 men $(31.2 \%)$. Median prostate-specific antigen at diagnosis was $7.1 \mathrm{ng} / \mathrm{ml}$ (IQR, 5.3-10.0 ng/ml). In most cases, clinical stage and biopsy Gleason score were $\mathrm{T} 1 / 2$ and $\leq 7$, respectively. Fifty-seven cases $(9.1 \%)$ were treated with neoadjuvant hormone therapy. Ipsilateral and bilateral nerve sparing were performed in 20.2 and $18.4 \%$ of cases, respectively. Lymph-node dissection was performed in $35.8 \%$ of cases. Resultant pathological profiles including tumor stage, Gleason score, resection margin status, and lympho-node involvement are listed in Table S1.

Perioperative outcomes are listed in Table S2. The median operation time was $235 \mathrm{~min}$ (IQR, 199-289 min), where the median console-operation time was $177 \mathrm{~min}$ (IQR, 144-234 min). The median estimated blood loss was $200 \mathrm{ml}$
(IQR, 100-350 ml). The median catheterization duration was 6 days (IQR, 5-7 days). The perioperative comorbidities with any grade and grade $\geq 3$ were documented in 100 patients (16.0\%) and 13 men (2.1\%), respectively. The perioperative complications with $>1 \%$ frequency were lymphorrhea or lymphocele $(3.0 \%)$, wound complications $(2.1 \%)$, urine leak $(1.8 \%)$, ileus $(1.1 \%)$, and postoperative hemorrhage $(1.1 \%)$.

Accordingly, clinical factors affecting the perioperative outcomes above were analyzed. First, we investigated the association with operation time. As shown in Table I, overweight, prostate volume, lymph-node dissection, and number of experienced cases were identified as factors affecting operation time on multivariate analysis. With regard to estimated blood loss, the associated factors with blood loss on multivariate analysis were identified as overweight, prostate volume, nerve sparing, lymph-node dissection, and number of experienced cases (Table II). Non-performance of lymph-node dissection and number of experienced cases were associated with decreased catheterization duration on multivariate analysis (Table III). Additionally, only performing lymph-node dissection was associated with increased for any 
Table III. Univariate and multivariate analyses of clinical factors affecting catheterization duration.

\begin{tabular}{|c|c|c|c|c|}
\hline \multirow[b]{2}{*}{ Variable } & \multicolumn{2}{|c|}{ Univariate analysis } & \multicolumn{2}{|c|}{ Multivariate analysis } \\
\hline & Mean (SEM) & P-value & Least squares mean (SEM) & P-value \\
\hline \multicolumn{5}{|l|}{ Age, years } \\
\hline$<65$ & $6.5(0.15)$ & & $6.6(0.20)$ & \\
\hline$\geq 65$ & $6.1(0.13)$ & $0.046^{\mathrm{a}}$ & $6.4(0.21)$ & 0.20 \\
\hline \multicolumn{5}{|l|}{ Overweight } \\
\hline Absence & $6.2(0.12)$ & & $6.3(0.20)$ & \\
\hline Presence & $6.6(0.18)$ & 0.078 & $6.7(0.22)$ & 0.092 \\
\hline \multicolumn{5}{|l|}{ Prostate volume, $\mathrm{ml}$} \\
\hline$<30$ & $6.2(0.12)$ & & $6.2(0.17)$ & \\
\hline $30 \leq x<50$ & $6.5(0.18)$ & & $6.7(0.21)$ & \\
\hline$\geq 50$ & $6.3(0.37)$ & 0.31 & $6.6(0.36)$ & 0.051 \\
\hline \multicolumn{5}{|l|}{ cT-stage } \\
\hline cT1 & $6.4(0.18)$ & & $6.6(0.21)$ & \\
\hline cT2 & $6.3(0.12)$ & & $6.6(0.17)$ & \\
\hline cT3 & $5.7(0.39)$ & 0.34 & $6.3(0.40)$ & 0.63 \\
\hline \multicolumn{5}{|l|}{ Nerve sparing } \\
\hline None & $6.1(0.12)$ & & $6.5(0.19)$ & \\
\hline Ipsilateral & $6.5(0.22)$ & & $6.4(0.26)$ & \\
\hline Bilateral & $6.9(0.23)$ & $0.0052^{\mathrm{b}}$ & $6.6(0.27)$ & 0.74 \\
\hline \multicolumn{5}{|l|}{ Lympho-node dissection } \\
\hline No procedure & $6.2(0.12)$ & & $6.2(0.20)$ & \\
\hline Underwent procedure & $6.4(0.16)$ & 0.40 & $6.8(0.22)$ & $0.0099^{\mathrm{b}}$ \\
\hline \multicolumn{5}{|c|}{ Number of experienced cases } \\
\hline $1-200$ & $7.6(0.16)$ & & $7.8(0.23)$ & \\
\hline $201-400$ & $5.9(0.16)$ & & $6.1(0.22)$ & \\
\hline $401-625$ & $5.5(0.15)$ & $<0.0001^{\mathrm{c}}$ & $5.6(0.22)$ & $<0.0001^{\mathrm{c}}$ \\
\hline
\end{tabular}

${ }^{\mathrm{a}} \mathrm{P}<0.05 ;{ }^{\mathrm{b}} \mathrm{P}<0.01 ;{ }^{\mathrm{c}} \mathrm{P}<0.0001$. SEM, standard error of mean.

grade of perioperative complications on multivariate analysis (Table IV).

\section{Discussion}

This prospective case series of RARP showed comparable perioperative outcomes to that of previous studies. Median operation time was 235 min while median or mean operative time was 90-291.1 min in previous studies, where lympho-node dissection was time-consuming as indicated Table I (7). Additionally, median estimated blood loss (200 ml) was comparable with that reported in previous studies $(69-534 \mathrm{ml})(7)$. Median catheterization duration (6 days) was also comparable with that for previous studies (5-11.4 days) (7). Furthermore, overall complication rate $(16.0 \%)$ was similar to that observed in previous studies (3-26\%) (7). Similarly, each complication rate in this study such as lymphorrhea or lymphocele $(3.0 \%)$, wound complications $(2.1 \%)$, and urine leak (1.8\%) were similar to those reported in previous studies (7).

In addition, this study has revealed clinical factors affecting perioperative outcomes in RARP such as operation time, estimated blood, catheterization duration, and perioperative complication, which are critical to both patients and surgeons. In this study, overweight, large prostate volume, and performing lymph-node dissection were risk factors of prolonged operation time. Consistently, both high body-mass index (18-20) and larger prostate volume (21-24) were previously identified as risk factors of longer operation time. Additionally, performing lymph-node dissection is a time-consuming procedure, resulting in longer operation time. Similarly, overweight, large prostate volume, and performing nerve sparing and lymph-node dissection were risk factors for increased estimated blood loss. Consistently, larger prostate volume was reported to be associated with increased blood loss (21-24). However, inconsistently, it was reported that higher body-mass index was not associated with increased blood loss in RARP $(18,19)$. Although this discrepancy may be due to differential prevalence of overweight and obesity between Western and Asian countries, further investigation would be required. Moreover, performing nerve sparing and lymph-node dissection are both procedures that require bleeding, resulting in increased blood loss. Thus, these parameters appeared to 
Table IV. Univariate and multivariate analyses on clinical factors affecting any grade perioperative complications.

\begin{tabular}{|c|c|c|c|c|}
\hline \multirow[b]{2}{*}{ Variable } & \multicolumn{2}{|c|}{ Univariate analysis } & \multicolumn{2}{|c|}{ Multivariate analysis } \\
\hline & Odd ratio $(95 \% \mathrm{CI})$ & P-value & Odd ratio $(95 \% \mathrm{CI})$ & P-value \\
\hline \multicolumn{5}{|l|}{ Age, years } \\
\hline$<65$ & Ref & & Ref & \\
\hline$\geq 65$ & $0.80(0.52-1.23)$ & 0.30 & $0.65(0.41-1.04)$ & 0.075 \\
\hline \multicolumn{5}{|l|}{ Overweight } \\
\hline Absence & Ref & & Ref & \\
\hline Presence & $1.05(0.65-1.64)$ & 0.85 & $1.09(0.67-1.76)$ & 0.74 \\
\hline \multicolumn{5}{|l|}{ Prostate volume, ml } \\
\hline$<30$ & Ref & & Ref & \\
\hline $30 \leq x<50$ & $1.14(0.71-1.81)$ & & $1.15(0.71-1.88)$ & \\
\hline$\geq 50$ & $1.20(0.53-2.70)$ & 0.82 & $1.57(0.67-3.68)$ & 0.56 \\
\hline \multicolumn{5}{|l|}{ cT-stage } \\
\hline cT1 & Ref & & Ref & \\
\hline cT2 & $1.39(0.85-2.29)$ & & $1.08(0.62-1.87)$ & \\
\hline сT3 & $1.46(0.58-3.66)$ & 0.39 & $0.60(0.22-1.67)$ & 0.42 \\
\hline \multicolumn{5}{|l|}{ Nerve sparing } \\
\hline None & Ref & & Ref & \\
\hline Ipsilateral & $0.52(0.26-0.94)$ & & $0.59(0.29-1.20)$ & \\
\hline Bilateral & $0.78(0.43-1.36)$ & 0.087 & $0.88(0.44-1.76)$ & 0.32 \\
\hline \multicolumn{5}{|l|}{ Lympho-node dissection } \\
\hline No procedure & Ref & & Ref & \\
\hline Underwent procedure & $3.30(2.13-5.16)$ & $<0.0001^{\mathrm{a}}$ & $3.70(2.23-6.14)$ & $<0.0001^{\mathrm{a}}$ \\
\hline \multicolumn{5}{|c|}{ Number of experienced cases } \\
\hline $1-200$ & Ref & & Ref & \\
\hline $201-400$ & $1.19(0.71-2.00)$ & & $0.96(0.54-1.71)$ & \\
\hline $401-625$ & $0.84(0.49-1.43)$ & 0.42 & $0.58(0.31-1.09)$ & 0.13 \\
\hline
\end{tabular}

${ }^{\mathrm{a}} \mathrm{P}<0.0001$. CI, confidence interval.

be robust factors for predicting operation time and blood loss. However, although number of experienced cases was identified a significant factor of operation time and blood loss, consistent tendency was not observed among number of experienced cases.

In addition, performing lymph-node dissection and number of experienced cases were associated with prolonged and reduced catheterization duration in our cohort, respectively. Since we reduced duration of catheterization as we become experienced, the number of experienced cases was obviously associated with reduced catheterization duration. Previously, prostate volume $(21,24)$, but not body-mass index (18) was reported to be associated with longer catheterization duration. However, this study failed to show significant results with prostate volume. Furthermore, performing lymph-node dissection was revealed to critically increase the risk of postoperative complication, which may, at least in part, be due to the complication with lymphorrhea or lymphocele. Therefore, the increased postoperative complication by performing lymph-node dissection may result in prolonged duration of catheterization. Previously, consistently with this study, most studies failed to demonstrate the association of body-mass index (18) and prostate volume (25) with perioperative complication rate although one report demonstrated the association of prostate volume with perioperative complication (21). Thus, high body-mass index did not appear to be associated with prolonged catheterization duration as well as increased complication rate in RARP. In this study focusing on RARP, overweight was not associated with prolonged catheterization duration and increased perioperative complication. However, perioperative complication was more frequent in obese men when treated with open radical prostatectomy, but not with RARP $(26,27)$. Thus, RARP has been suggested to overcome the challenging situation in obese men by its refined operability with advanced technology, resulting in reduced perioperative complication.

The present study had several limitations. First, operation was performed during relatively long periods of 8 years by seven surgeons with varied experiences using their slightly different procedures, which were not included as parameters. Second, non-severe perioperative complications might be overlooked in some cases. Finally, this study may not include 
a possible risk factor influencing perioperative outcomes such as preoperative comorbidities and the presence of median lobe of prostate.

In conclusion, this study identified several risk factors affecting perioperative outcomes in RARP. This information will help surgeons to estimate perioperative outcomes as well as inform to patients. In addition, overweight was associated with longer operation time and increased blood loss, but not with longer catheterization duration and increased complication rate, suggesting RARP may overcome challenging situations in obese men, resulting in reduced perioperative complication.

\section{Acknowledgements}

Not applicable.

\section{Funding}

No funding was received.

\section{Availability of data and materials}

The datasets used and/or analyzed during the current study are available from the corresponding author on reasonable request.

\section{Authors' contributions}

TM and MS drafted the manuscript and performed the statistical analysis. TM, SO, RN, MS, JI, AT and EK performed the procedures to obtain the data. MS, JI, KT and ME conducted the treatments. MS designed the study. ME supervised the study. All of the authors have read and approved the final version of this manuscript.

\section{Ethics approval and consent to participate}

The study protocol was approved by the Ethics Committee of Kyushu University (Fukuoka, Japan). The research was conducted in accordance with the Declaration of Helsinki. All patients provided written informed consent.

\section{Patient consent for publication}

The right of opt-out was provided to all patients.

\section{Competing interests}

The authors declare that they have no competing interests.

\section{References}

1. Siegel RL, Miller KD and Jemal A: Cancer statistics, 2017. CA Cancer J Clin 67: 7-30, 2017.

2. Bill-Axelson A, Holmberg L, Garmo H, Rider JR, Taari K, Busch C, Nordling S, Häggman M, Andersson SO, Spångberg A, et al: Radical prostatectomy or watchful waiting in early prostate cancer. N Engl J Med 370: 932-942, 2014.

3. Wilt TJ, Brawer MK, Jones KM, Barry MJ, Aronson WJ, Fox S, Gingrich JR, Wei JT, Gilhooly P, Grob BM, et al: Radical prostatectomy versus observation for localized prostate cancer. N Engl J Med 367: 203-213, 2012.
4. Bach C, Pisipati S, Daneshwar D, Wright M, Rowe E, Gillatt D, Persad $R$ and Koupparis A: The status of surgery in the management of high-risk prostate cancer. Nat Rev Urol 11: 342-351, 2014.

5. Metcalfe MJ, Smaldone MC, Lin DW, Aparicio AM and Chapin BF: Role of radical prostatectomy in metastatic prostate cancer: A review. Urol Oncol 35: 125-134, 2017.

6. Trinh QD, Sammon J, Sun M, Ravi P, Ghani KR, Bianchi M, Jeong W, Shariat SF, Hansen J, Schmitges J, et al: Perioperative outcomes of robot-assisted radical prostatectomy compared with open radical prostatectomy: Results from the nationwide inpatient sample. Eur Urol 61: 679-685, 2012.

7. Novara G, Ficarra V, Rosen RC, Artibani W, Costello A, Eastham JA, Graefen M, Guazzoni G, Shariat SF, Stolzenburg JU, et al: Systematic review and meta-analysis of perioperative outcomes and complications after robot-assisted radical prostatectomy. Eur Urol 62: 431-452, 2012.

8. Gandaglia G, Sammon JD, Chang SL, Choueiri TK, Hu JC, Karakiewicz PI, Kibel AS, Kim SP, Konijeti R, Montorsi F, et al: Comparative effectiveness of robot-assisted and open radical prostatectomy in the postdissemination era. J Clin Oncol 32: 1419-1426, 2014.

9. Agarwal PK, Sammon J, Bhandari A, Dabaja A, Diaz M, Dusik-Fenton S, Satyanarayana R, Simone A, Trinh QD, Baize B and Menon M: Safety profile of robot-assisted radical prostatectomy: A standardized report of complications in 3317 patients. Eur Urol 59: 684-698, 2011.

10. Khaira HS, Bruyere F, O'Malley PJ, Peters JS and Costello AJ: Does obesity influence the operative course or complications of robot-assisted laparoscopic prostatectomy. BJU Int 98: 1275-1278, 2006.

11. Chalasani V, Martinez CH, Lim D, Bareeq RA, Wignall GR, Stitt L and Pautler SE: Impact of body mass index on perioperative outcomes during the learning curve for robot-assisted radical prostatectomy. Can Urol Assoc J 4: 250-254, 2010.

12. Abdul-Muhsin H, Giedelman C, Samavedi S, Schatloff O, Coelho R, Rocco B, Palmer K, Ebra G and Patel V: Perioperative and early oncological outcomes after robot-assisted radical prostatectomy (RARP) in morbidly obese patients: A propensity score-matched study. BJU Int 113: 84-91, 2014.

13. Shiota M, Yokomizo A, Takeuchi A, Imada K, Kiyoshima K, Inokuchi J, Tatsugami $\mathrm{K}$ and Naito $\mathrm{S}$ : The feature of metabolic syndrome is a risk factor for biochemical recurrence after radical prostatectomy. J Surg Oncol 110: 476-481, 2014.

14. Shiota M, Takeuchi A, Sugimoto M, Kashiwagi E, Dejima T, Kiyoshima K, Inokuchi J, Tatsugami K, Yokomizo A and Eto M: The differential impact of body mass index and the feature of metabolic syndrome on oncological outcomes following different surgical procedures in japanese men with prostate cancer. Ann Surg Oncol 24: 1443-1450, 2017.

15. D'Amico AV, Whittington R, Malkowicz SB, Schultz D, Blank K, Broderick GA, Tomaszewski JE, Renshaw AA, Kaplan I, Beard CJ and Wein A: Biochemical outcome after radical prostatectomy, external beam radiation therapy, or interstitial radiation therapy for clinically localized prostate cancer. JAMA 280: 969-974, 1998.

16. Naito S, Kuroiwa K, Kinukawa N, Goto K, Koga H, Ogawa O, Murai M and Shiraishi T; Clinicopathological Research Group for Localized Prostate Cancer Investigators: Validation of Partin tables and development of a preoperative nomogram for Japanese patients with clinically localized prostate cancer using 2005 International Society of Urological Pathology consensus on Gleason grading: Data from the Clinicopathological Research Group for Localized Prostate Cancer. J Urol 180: 904-910, 2008.

17. Dindo D, Demartines N and Clavien PA: Classification of surgical complications: A new proposal with evaluation in a cohort of 6336 patients and results of a survey. Ann Surg 240: 205-213, 2004.

18. Wiltz AL, Shikanov S, Eggener SE, Katz MH, Thong AE, Steinberg GD, Shalhav AL,Zagaja GP and Zorn KC: Robotic radical prostatectomy in overweight and obese patients: Oncological and validated-functional outcomes. Urology 73: 316-322, 2009.

19. Moskovic DJ, Lavery HJ, Rehman J, Nabizada-Pace F, Brajtbord J and Samadi DB: High body mass index does not affect outcomes following robotic assisted laparoscopic prostatectomy. Can J Urol 17: 5291-5298, 2010.

20. Zilberman DE, Tsivian M, Yong D and Albala DM: Surgical steps that elongate operative time in robot-assisted radical prostatectomy among the obese population. J Endourol 25: 793-796, 2011. 
21. Link BA, Nelson R, Josephson DY, Yoshida JS, Crocitto LE, Kawachi MH and Wilson TG: The impact of prostate gland weight in robot assisted laparoscopic radical prostatectomy. J Urol 180: 928-932, 2008.

22. Martínez CH, Chalasani V, Lim D, Nott L, Al-Bareeq RJ, Wignall GR, Stitt L and Pautler SE: Effect of prostate gland size on the learning curve for robot-assisted laparoscopic radical prostatectomy: Does size matter initially? J Endourol 24: 261-266, 2010.

23. Skolarus TA, Hedgepeth RC, Zhang Y, Weizer AZ, Montgomery JS, Miller DC, Wood DP Jr and Hollenbeck BK: Does robotic technology mitigate the challenges of large prostate size? Urology 76: 1117-1121, 2010.

24. Huang AC, Kowalczyk KJ, Hevelone ND, Lipsitz SR, Yu HY, Plaster BA, Amarasekara CA, Ulmer WD, Lei Y, Williams SB and Hu JC: The impact of prostate size, median lobe, and prior benign prostatic hyperplasia intervention on robot-assisted laparoscopic prostatectomy: Technique and outcomes. Eur Urol 59: 595-603, 2011
25. Allaparthi SB, Hoang T, Dhanani NN and Tuerk IA: Significance of prostate weight on peri and postoperative outcomes of robot assisted laparoscopic extraperitoneal radical prostatectomy. Can J Urol 17: 5383-5389, 2010.

26. Bae JJ, Choi SH, Kwon TG and Kim TH: Advantages of robot-assisted laparoscopic radical prostatectomy in obese patients: Comparison with the open procedure. Korean J Urol 53: 536-540, 2012

27. Monn MF, Jaqua KR, Calaway AC, Mellon MJ, Koch MO and Boris RS: Impact of obesity on wound complications following radical prostatectomy is mitigated by robotic technique. J Endourol 30: 890-895, 2016. 